\title{
Methodological assessment of guidelines for the diagnosis and management of cerebral vasospasm using the AGREE-II tool
}

\author{
Anastasia Tasiou, MD, PhD, Alexandros G. Brotis, MD, PhD, Christos Tzerefos, MD, \\ Xanthoula Lambrianou, MD, and Kostas N. Fountas, MD, PhD \\ Department of Neurosurgery, University Hospital of Larissa, Faculty of Medicine, School of Health Sciences, University of \\ Thessaly, Larissa, Greece
}

\begin{abstract}
OBJECTIVE Rupture of an intracranial aneurysm is the most common cause of spontaneous subarachnoid hemorrhage. Despite the recent advances in its early detection, diagnosis, and proper treatment, the outcome of patients experiencing aneurysmal subarachnoid hemorrhage (aSAH) remains poor. It is well known that cerebral vasospasm is the most troublesome complication of aSAH, while delayed cerebral ischemia related to cerebral vasospasm constitutes the major cause of unfavorable outcomes in patients with aSAH. The need for evidence-based guidelines is of great importance for the prevention, early detection, and efficient management of aSAH-induced vasospasm. Moreover, guidelines provide young physicians with a valuable tool for practicing defensible medicine. However, the methodology, clinical applicability, reporting clarity, and biases of guidelines must be periodically assessed. In this study, the authors sought to assess the reporting clarity and methodological quality of published guidelines and recommendations.
\end{abstract}

METHODS A search was performed in the PubMed, Scopus, and Web of Science databases. The search terms used were "clinical practice guidelines," "recommendations," "stroke," "subarachnoid hemorrhage," and "vasospasm" in all possible combinations. The search period extended from 1964 to September 2021 and was limited to literature published in the English language. All published guidelines and recommendations reporting on the diagnosis and management of vasospasm were included. Studies other than those reporting guidelines and recommendations were excluded. The eligible studies were evaluated by three blinded raters, employing the Appraisal of Guidelines for Research \& Evaluation II (AGREE-II) analysis tool.

RESULTS A total of 10 sets of guidelines were evaluated in this study. The American Heart Association/American Stroke Association issued guidelines found to have the highest methodological quality and reporting clarity, followed by the European Stroke Organization guidelines and the English edition of the Japanese guidelines issued by the Japanese Society on Surgery for Cerebral Stroke. The interrater agreement was moderate in the current analysis.

CONCLUSIONS These findings support the idea that improvement of currently existing guidelines is feasible in the following domains: the rigor of guidelines and recommendations development, clinical applicability, editorial independence, and stakeholder involvement. Furthermore, periodic updating of published guidelines requires improvement in the future. https://thejns.org/doi/abs/10.3171/2021.12.FOCUS21649

KEYWORDS AGREE-II; aneurysmal subarachnoid hemorrhage; guidelines; management; recommendations; vasospasm

$\mathrm{R}$ UPTURE of an intracranial aneurysm is the most common cause of spontaneous subarachnoid hemorrhage. ${ }^{1}$ The incidence of aneurysmal subarachnoid hemorrhage (aSAH) ranges from 2 to 16 per 100,000 population. ${ }^{2}$ Although aSAH constitutes a common clinicopathological entity, its management remains challenging; its underlying pathophysiological mechanisms remain unclear and its prognosis is often dismal.,4 Despite the recent advances in early detection, diagnosis, and proper treatment, the overall outcome of patients with aSAH remains poor. ${ }^{5}$

Cerebral vasospasm is the most troublesome complication of aSAH. It is well known that the presence of oxyhemoglobin plays a key role in the observed arterial narrowing (vasospasm) after aSAH. ${ }^{6}$ The occurrence of cerebral vasospasm varies significantly. It has been demonstrated to

ABBREVIATIONS AGREE- $\|$ = Appraisal of Guidelines for Research \& Evaluation II; AHA = American Heart Association; $A$ SA = American Stroke Association; aSAH = aneurysmal subarachnoid hemorrhage; $\mathrm{CK}=$ Cohen's kappa; $\mathrm{CPG}=$ clinical practice guidelines; $\mathrm{CPR}=$ clinical practice recommendation; $\mathrm{DCl}=$ delayed cerebral ischemia; ESO = European Stroke Organization; TCD = transcranial Doppler.

SUBMITTED October 28, 2021. ACCEPTED December 21, 2021. INCLUDE WHEN CITING DOI: 10.3171/2021.12.FOCUS21649. 
TABLE 1. Systematic search strategy based on the PICO criteria

\begin{tabular}{|c|c|c|c|c|c|}
\hline Frame & Keywords & Search & Inclusion Criteria & Exclusion Criteria & Sources \\
\hline Population & $\begin{array}{l}\text { \#1. "adults" \#2. "subarachnoid } \\
\text { hemorrhage" OR "sub- } \\
\text { arachnoid hemorrhage" OR } \\
\text { "aSAH" OR "stroke" }\end{array}$ & $\begin{array}{l}\text { \#1 AND } \\
\text { \#2 AND } \\
\text { \#3 AND } \\
\text { \#4 }\end{array}$ & $\begin{array}{l}\text { CPGs reporting on the } \\
\text { diagnosis \& manage- } \\
\text { ment of cerebral } \\
\text { vasospasm associated } \\
\text { w/ aSAH; published } \\
\text { in peer-reviewed jour- } \\
\text { nals; English-language } \\
\text { articles }\end{array}$ & $\begin{array}{l}\text { CPGs not reporting on vasospasm } \\
\text { associated w/ aSAH; CPGs on pedi- } \\
\text { atric population or ischemic stroke; } \\
\text { non-English language; irrelevant title } \\
\text { or abstract; irrelevant full text; study } \\
\text { design other than CPGs, including } \\
\text { editorials, reviews, letters to the editor, } \\
\text { meta-analyses, original studies, \& } \\
\text { experimental nonhuman studies }\end{array}$ & $\begin{array}{l}\text { Databases } \\
\text { (PubMed, } \\
\text { Scopus, \& Web } \\
\text { of Science); } \\
\text { reference list } \\
\text { of the gathered } \\
\text { records }\end{array}$ \\
\hline Intervention & Not specified & & & & \\
\hline Comparator & Not specified & & & & \\
\hline Outcome & \#3. "vasospasm" & & & & \\
\hline Study design & $\begin{array}{l}\text { \#4. "clinical practice guidelines" } \\
\text { OR "recommendations" }\end{array}$ & & & & \\
\hline Time & $\begin{array}{l}\text { Search period: } 1964-2021 \text {; last } \\
\text { search: September } 2021\end{array}$ & & & & \\
\hline
\end{tabular}

be as high as $70 \%$ based on angiographic findings, while in $20 \%$ to $30 \%$ of patients vasospasm is associated with clinical deterioration due to the development of delayed cerebral ischemia (DCI) or a cerebral infarct. ${ }^{7.8}$ DCI related to cerebral vasospasm is the major cause of unfavorable functional outcomes associated with aSAH. Although a growing body of evidence suggests that the development of vasospasm is not the only underlying triggering event for cerebral ischemia, its prevention, and its proper management in a timely fashion, constitutes a requisite for the efficacious management of patients with aSAH.

The need for evidence-based guidelines on different clinical topics, particularly complex pathological entities such as aSAH-induced vasospasm, cannot be overemphasized. Guidelines are of paramount importance for the prevention, accurate and early diagnosis, and efficacious management of the post-SAH vasospasm. This may mitigate complications and may improve the overall clinical outcome of this patient population. Moreover, management guidelines are important for establishing an easy and proliferative communication among the physicians managing these patients.

The purpose of the current study was to assess the reporting clarity and methodological quality of the guidelines and recommendations regarding the diagnosis and management of aSAH-induced vasospasm according to the Appraisal of Guidelines for Research \& Evaluation II (AGREE-II) tool. ${ }^{9}$

\section{Methods}

\section{Search Strategy}

The current study was carried out in three steps. First, we performed a systematic electronic literature search looking for published clinical practice guidelines (CPGs) or clinical practice recommendations (CPRs) focusing on vasospasm associated with aSAH. We searched with the keywords "clinical practice guidelines," "recommendations," "vasospasm," "subarachnoid hemorrhage," and "stroke" using the strategy depicted in Table 1 . The electronic search was carried out in PubMed, Scopus, and Web of Science for the period from 1964 to September 2021. The search was limited to articles published in the English language. Additional CPGs were traced in the reference list of the retrieved articles.

\section{Selection Process}

The second step was a study selection process. We set the eligibility criteria prospectively, during the design of the study. Notably, the AGREE-II tool does not provide any eligibility criteria. We followed a more inclusive approach; therefore, we included all published CPGs and CPRs that reported on the diagnosis and management of vasospasm after aSAH, even if they primarily focused on relevant clinical entities, such as stroke. Each CPG and CPR was identified by the name of the first author and the year of publication. For the study selection, three authors (C.T., X.L., and A.G.B.) assessed the titles and abstracts to eliminate records based on the exclusion criteria. We excluded articles other than CPGs and CPRs; those without any comment on vasospasm in the title, abstract, and/ or full text; CPGs and CPRs written in languages other than English; and articles involving pediatric populations. A senior author (K.N.F.) was consulted in the case of disagreement.

\section{CPG and CPR Appraisal}

In the third step, we appraised the eligible CPGs and CPRs using the AGREE-II tool, a Likert-based subjective evaluation scale. It should be noted that an evaluator bias cannot be excluded. The full texts of the gathered recommendations and their updated versions, including their supplements, were thoroughly assessed for the appraisal process. The raters conducted, independently and blindly, the article review and scoring processes, after having previously completed the AGREE-II online training. None had participated in the writing or the development of any of the retrieved publications. 
The AGREE-II tool consists of 23 items organized in 6 domains (scope and purpose, stakeholder involvement, rigor of development, clarity of presentation, applicability, and editorial independence), and 2 additional items regarding the overall assessment. Each item of the 6 domains was rated on a 7-point Likert scale (1, strongly disagree to 7 , strongly agree). The overall assessment was scored using the 7-point Likert scale, as well as an ordinal 3 -tier scale (recommend, recommend with modifications, or not recommended). The overall assessment represented the evaluator judgment regarding the quality of the guidelines, taking into consideration the criteria considered in the assessment process. ${ }^{9}$ Domain scores were calculated by summing up all the scores of individual items, and by scaling the total as a percentage (or decimal) of the maximum possible score for that domain according to the AGREE-II tutorial. ${ }^{9}$ At present, no specific quality thresholds exist for determining high- and low-quality guidelines. The domain scores were categorized as "high" ( $\geq 80 \%)$, "medium" (60\%-79\%), "low" (40\%-59\%), and "very low" $(<40 \%)$. The degree of agreement between raters was determined by Cohen's kappa (CK). A value from 0 to 0.19 was considered as "no agreement," 0.20 to 0.39 as "minimal agreement," 0.40 to 0.59 as "weak agreement," 0.60 to 0.79 as "moderate agreement," 0.80 to 0.90 as "strong agreement," and $>0.90$ as "almost perfect agreement." The results were presented in tables and visualized in bar graphs. All statistical analyses were performed using Excel (Microsoft) and the Real Statistics (https://www.real-statistics.com) package.

\section{Results \\ Study Selection}

A total of 26,661 nonduplicate citations were retrieved during our electronic literature search. During the title and abstract screening, 26,634 irrelevant articles were discarded. Fourteen additional articles were discarded after full-text screening. Finally, 13 sets of guidelines fulfilled our eligibility criteria.

\section{Eligible CPGs and CPRs}

Of the 13 gathered CPGs and CPRs, 3 records represented updates of previously reported recommendations. For our guideline appraisal, we discarded all outdated versions, and the remaining 10 formed the basis of our analysis. The included guidelines focused on the management of aSAH $(n=7,70 \%)$, stroke in general $(n=2$, $20 \%)$, and vasospasm $(\mathrm{n}=1,10 \%)$. They were published between 2011 and 2019, mostly from international multidisciplinary scientific organizations $(n=4,40 \%)$ and from national or regional multidisciplinary medical societies (n $=6,60 \%)($ Table 2).

\section{Critical Appraisal}

The overall guideline assessment ranged from 22.3\% to $83.3 \%$ (Fig. 1 and Table 3). The American Heart Association (AHA)/American Stroke Association (ASA) guidelines by Connolly et al. achieved the highest score (83.3\%) in terms of methodological quality and reporting clarity, followed by the European Stroke Organization
(ESO) guidelines by Steiner et al. (77.8\%) and the Japanese guidelines (English edition) by the Japanese Society on Surgery for Cerebral Stroke (66.7\%). ${ }^{10-12}$ On the contrary, the lowest scores were recorded for the International Multidisciplinary Consensus on the endovascular management of cerebral vasospasm by Kimball et al. (22.3\%) and the Chinese Stroke Association guidelines on the clinical management of cerebrovascular disorders by Dong et al. $(50 \%) .13,14$

The mean domain score was $61.7 \%$, ranging from $0.0 \%$ to $81 \%$ (Table 3). The gathered body of guidelines was of "high" quality in terms of the scope and purpose domain (mean $81 \%$ ), and of "medium" quality regarding the clarity of presentation (mean 78.3\%) and the overall guideline assessment (mean 61.7\%). The remaining examined domains were of "low" methodological clarity.

The overall agreement between the three raters was moderate (CK 0.718) (Fig. 2 and Table 3). The raters showed "strong agreement" in scoring the ESO guidelines (CK 0.820), Korean guidelines on aSAH (CK 0.813), and International Multidisciplinary Consensus guidelines on endovascular management of cerebral vasospasm by Kimball et al. (CK 0.811). ${ }^{11,13,17}$ Contrariwise, there was a weak agreement between the raters regarding the Canadian best practice recommendations on stroke (CK 0.446). ${ }^{19}$

\section{Discussion \\ Background}

Aneurysmal SAH constitutes a serious and acute medical condition for which the outcome remains dismal. One of the most common causes of death and severe disability in patients with aSAH is cerebral vasospasm. It is noteworthy that vasospasm is not simply the narrowing of large cerebral arteries visible on DSA, but a complex dysfunction at the microcirculatory level. This phenomenon explains why vasospasm-induced ischemia is not always proportional to the severity of large artery vasospasm. It is well known that there are patients with severe vasospasm who remain asymptomatic, and patients with modest vasospasm who become symptomatic and may develop cerebral infarction. Postvasospasm DCI seems to be multifactorial in origin and complex from a pathophysiological standpoint. On the other hand, there is a growing body of evidence that vasospasm is not the only factor contributing to the development of DCI. However, in cases in which vasospasm appears and may be reversible, accurate and early recognition and proper management become of paramount importance. Evidence-based guidelines are a useful tool for a comprehensive and integrated approach to managing patients with aSAH, especially regarding the diagnosis and management of cerebral vasospasm. Emphasis should be given not only to the quality of the data but also to the implementation of these data into daily clinical practice.

\section{AGREE-II Appraisal}

AGREE-II is a tool for assessing the reporting clarity and methodological quality of guidelines and recommendations. ${ }^{9}$ In the current study, we used AGREE-II for evaluating the clarity and quality of the guidelines regarding diagnosis and management of aSAH-induced cerebral va- 
TABLE 2. Eligible guidelines and recommendations reported on the management of vasospasm associated with aSAH

\begin{tabular}{|c|c|c|c|}
\hline Authors \& Year & Title & Journal & Issuing Body \\
\hline Diringer et al., $2011^{15}$ & $\begin{array}{l}\text { "Critical care management of patients following aneurysmal sub- } \\
\text { arachnoid hemorrhage: recommendations from the Neurocritical } \\
\text { Care Society's Multidisciplinary Consensus Conference" }\end{array}$ & Neurocritical Care & $\begin{array}{l}\text { Neurocritical Care Soci- } \\
\text { ety's Multidisciplinary } \\
\text { Consensus }\end{array}$ \\
\hline Quinn et al., $2011^{18}$ & $\begin{array}{l}\text { "Evidenced based guidelines for the management of good grade sub- } \\
\text { arachnoid haemorrhage patients in Leeds, UK" }\end{array}$ & $\begin{array}{l}\text { Acta Neurochirgica } \\
\text { Supplement }\end{array}$ & $\begin{array}{l}\text { Leeds (United Kingdom) } \\
\text { Regional Multidisci- } \\
\text { plinary Medical Societies }\end{array}$ \\
\hline Kimball et al., $2011^{13}$ & $\begin{array}{l}\text { "Critical care guidelines on the endovascular management of cere- } \\
\text { bral vasospasm" }\end{array}$ & Neurocritical Care & $\begin{array}{l}\text { International Multidisci- } \\
\text { plinary Consensus }\end{array}$ \\
\hline Connolly et al., $2012^{10}$ & $\begin{array}{l}\text { "Guidelines for the management of aneurysmal subarachnoid hemor- } \\
\text { rhage: a guideline for healthcare professionals from the American } \\
\text { Heart Association/American Stroke Association" }\end{array}$ & Stroke & AHA/ASA \\
\hline $\begin{array}{l}\text { Committee for Guide- } \\
\text { lines for Management of } \\
\text { Aneurysmal Subarachnoid } \\
\text { Hemorrhage, Japanese } \\
\text { Society on Surgery for } \\
\text { Cerebral Stroke, } 2012^{12}\end{array}$ & $\begin{array}{l}\text { "Evidence-based guidelines for the management of aneurysmal sub- } \\
\text { arachnoid hemorrhage. English Edition" }\end{array}$ & $\begin{array}{l}\text { Neurologia Medi- } \\
\text { co-Chirurgica }\end{array}$ & $\begin{array}{l}\text { Japanese Society on Sur- } \\
\text { gery for Cerebral Stroke }\end{array}$ \\
\hline Steiner et al., $2013^{11}$ & $\begin{array}{l}\text { "European Stroke Organization guidelines for the management of } \\
\text { intracranial aneurysms and subarachnoid haemorrhage" }\end{array}$ & $\begin{array}{l}\text { Cerebrovascular } \\
\text { Diseases (Basel, } \\
\text { Switzerland) }\end{array}$ & $\begin{array}{l}\text { European Stroke Organiza- } \\
\text { tion }\end{array}$ \\
\hline Solter et al., $2014^{16}$ & $\begin{array}{l}\text { "Recommendations for the management of medical complications in } \\
\text { patients following aneurysmal subarachnoid hemorrhage" }\end{array}$ & $\begin{array}{l}\text { Acta Clinica } \\
\text { Croatica }\end{array}$ & $\begin{array}{l}\text { Croatian Multidisciplinary } \\
\text { Medical Societies }\end{array}$ \\
\hline Casaubon et al., $2015^{19}$ & $\begin{array}{l}\text { "Canadian stroke best practice recommendations: hyperacute stroke } \\
\text { care guidelines, update } 2015 \text { " }\end{array}$ & $\begin{array}{l}\text { International Jour- } \\
\text { nal of Stroke }\end{array}$ & $\begin{array}{l}\text { Heart and Stroke Founda- } \\
\text { tion of Canada }\end{array}$ \\
\hline Cho et al., $2018^{17}$ & $\begin{array}{l}\text { "Korean clinical practice guidelines for aneurysmal subarachnoid } \\
\text { hemorrhage" }\end{array}$ & $\begin{array}{l}\text { Journal of Korean } \\
\text { Neurosurgery }\end{array}$ & $\begin{array}{l}\text { Korean Multidisciplinary } \\
\text { Medical Societies }\end{array}$ \\
\hline Dong et al., $2019^{14}$ & $\begin{array}{l}\text { "Chinese Stroke Association guidelines for clinical management of } \\
\text { cerebrovascular disorders: executive summary and } 2019 \text { update of } \\
\text { clinical management of spontaneous subarachnoid haemorrhage" }\end{array}$ & $\begin{array}{l}\text { Stroke and Vascu- } \\
\quad \text { lar Neurology }\end{array}$ & Chinese Stroke Association \\
\hline
\end{tabular}

sospasm. In terms of methodological quality and reporting clarity, we found that the AHA/ASA guidelines achieved the highest score $(83.3 \%)$, followed by the ESO $(77.8 \%)$ and the Japanese $(66.7 \%)$ guidelines. ${ }^{10-12}$ Contrariwise, the lowest scores were recorded for the International Multidisciplinary Consensus guidelines on the endovascular management of cerebral vasospasm by Kimball et al. and the Chinese Stroke Association guidelines (22.3\% and 50\%, respectively). ${ }^{13,14}$ The overall guideline assessment ranged from $22.3 \%$ to $83.3 \%$, with a mean of $61.7 \%$.

\section{Guidelines on Diagnosis and Management of Cerebral Vasospasm}

With regard to the diagnosis of vasospasm, most of the published recommendations postulate that, since repeat neurological examination is limited to patients with good grades, transcranial Doppler (TCD) ultrasonography is a practical, noninvasive, and reliable predictor of cerebral vasospasm. ${ }^{10,12,15-17}$ Although TCD evaluation is feasible on a daily basis, its accuracy is highly operator dependent. Promising monitoring modalities include high-quality CTA and perfusion imaging, such as CT perfusion and/ or MR perfusion..$^{10,12,15-17}$ However, DSA remains the gold standard for detection of angiographically visible cerebral vasospasm. ${ }^{15-17}$
All but one of the published guidelines recommended that oral nimodipine, a calcium channel blocker, should be administered to all patients with aSAH..$^{10,11,14-19}$ The dogma that nimodipine administration improves cerebral vasospasm has been abandoned; nowadays, we know that nimodipine improves the overall functional outcome in patients with vasospasm-induced DCI. ${ }^{20,21}$ Nimodipine administration is not yet approved in Japan; therefore, an alternative medication, fasudil hydrochloride, is recommended by the Japanese guidelines. ${ }^{12}$

Moreover, the literature has shifted from the traditional triple- $\mathrm{H}$ therapy to the maintenance of euvolemia, ${ }^{10,11,16,19}$ although there are centers around the world that still employ triple-H therapy as a first-line management of symptomatic vasospasm. ${ }^{15,18}$ Prophylactic hypervolemia is no longer recommended. ${ }^{10}$ Induced hemodynamic augmentation with induced hypertension is recommended only in patients diagnosed with DCI ${ }^{10,12,16,17,19}$ This therapy should be individualized, and it should be avoided in patients with unsecured aneurysms.

In patients who do not respond to hemodynamic augmentation, endovascular intervention is suggested. Most guidelines agree that prophylactic endovascular treatment is not reasonable or justified by the available evidence. In patients who are symptomatic, either pharmaceutical, us- 


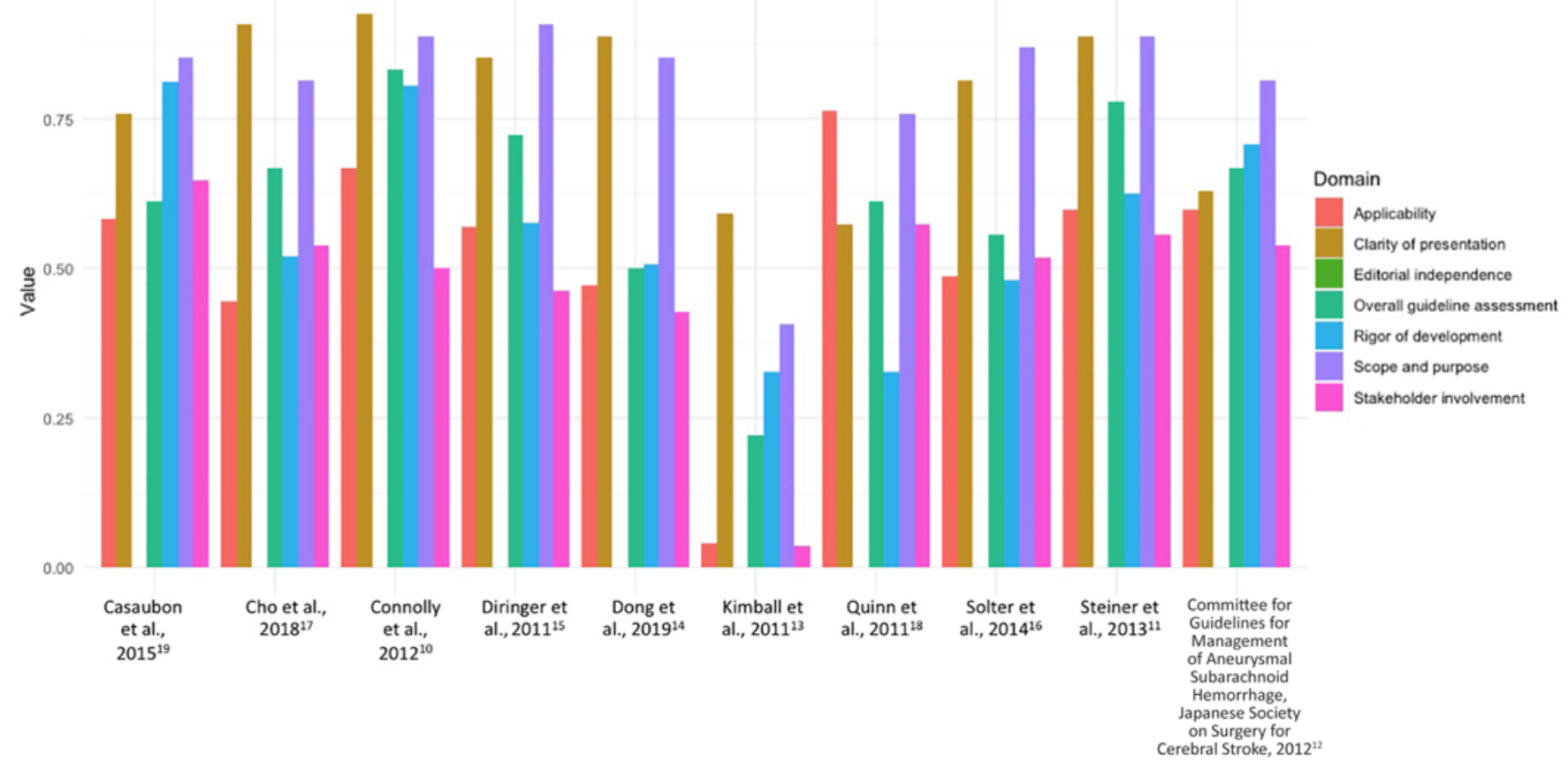

FIG. 1. Side-by-side bar graph visualizing the critical appraisal of vasospasm guidelines using the AGREE-II tool. Each color corresponds to one of the 7 AGREE-II domains. The length of each bar is proportional to the score of a certain domain (range $0.0-1.0)$. Notably, editorial independence is extremely low. It becomes apparent that the AHA/ASA guidelines by Connolly et al. ${ }^{10}$ had the highest methodological quality and reporting clarity.

ing intra-arterial vasodilators, or mechanical, using cerebral balloon angioplasty, endovascular therapy is recommended. ${ }^{10,12-17,19}$ All relevant data and recommendations are summarized in Table 4.

\section{Applicability of AGREE-II Analysis}

The current guideline appraisal was intended to iden- tify and thoroughly review the existing CPGs and CPRs to elucidate areas that could be improved in future versions. It provides a quantitative analysis assessing the clinical applicability of the existing guidelines. Moreover, the analysis examined the rigor of development, enlightening issues of methodological clarity. Our findings support that higher-quality guidelines were based on a systematic and

TABLE 3. Summary of the critical appraisal of clinical practice recommendations and guidelines according to AGREE-II

\begin{tabular}{|c|c|c|c|c|c|c|c|c|}
\hline Authors \& Year & $\begin{array}{l}\text { Scope \& } \\
\text { Purpose }\end{array}$ & $\begin{array}{l}\text { Stakeholder } \\
\text { Involvement }\end{array}$ & $\begin{array}{c}\text { Rigor of } \\
\text { Development }\end{array}$ & $\begin{array}{c}\text { Clarity of } \\
\text { Presentation }\end{array}$ & Applicability & $\begin{array}{c}\text { Editorial } \\
\text { Independence }\end{array}$ & $\begin{array}{c}\text { Overall Guideline } \\
\text { Assessment }\end{array}$ & $\mathrm{CK}$ \\
\hline Diringer et al., $2011^{15}$ & 0.907 & 0.463 & 0.576 & 0.852 & 0.569 & 0.000 & 0.722 & 0.791 \\
\hline Quinn et al., $2011^{18}$ & 0.759 & 0.574 & 0.326 & 0.574 & 0.764 & 0.000 & 0.611 & 0.728 \\
\hline Kimball et al., $2011^{13}$ & 0.407 & 0.037 & 0.326 & 0.593 & 0.042 & 0.000 & $0.223^{*}$ & 0.811 \\
\hline Connolly et al., $2012^{10}$ & 0.889 & 0.500 & 0.806 & 0.926 & 0.667 & 0.000 & $0.833 \dagger$ & 0.671 \\
\hline $\begin{array}{l}\text { Committee for Guidelines for } \\
\text { Management of Aneurysmal } \\
\text { Subarachnoid Hemorrhage, } \\
\text { Japanese Society on Surgery for } \\
\text { Cerebral Stroke, } 2012^{12}\end{array}$ & 0.815 & 0.537 & 0.708 & 0.630 & 0.597 & 0.000 & 0.667 & 0.784 \\
\hline Steiner et al., $2013^{11}$ & 0.889 & 0.556 & 0.625 & 0.889 & 0.597 & 0.000 & 0.778 & 0.820 \\
\hline Solter et al., $2014^{16}$ & 0.870 & 0.519 & 0.479 & 0.815 & 0.486 & 0.000 & 0.556 & 0.701 \\
\hline Casaubon et al., $2015^{19}$ & 0.852 & 0.648 & 0.813 & 0.759 & 0.583 & 0.000 & 0.611 & 0.446 \\
\hline Cho et al., $2018^{17}$ & 0.815 & 0.537 & 0.521 & 0.907 & 0.444 & 0.000 & 0.667 & 0.813 \\
\hline Dong et al., $2019^{14}$ & 0.852 & 0.426 & 0.507 & 0.889 & 0.472 & 0.000 & 0.500 & 0.615 \\
\hline Mean & 0.81 & 0.480 & 0.569 & 0.783 & 0.522 & 0.000 & 0.617 & 0.718 \\
\hline
\end{tabular}

* Lowest score.

$\dagger$ †ighest score. 


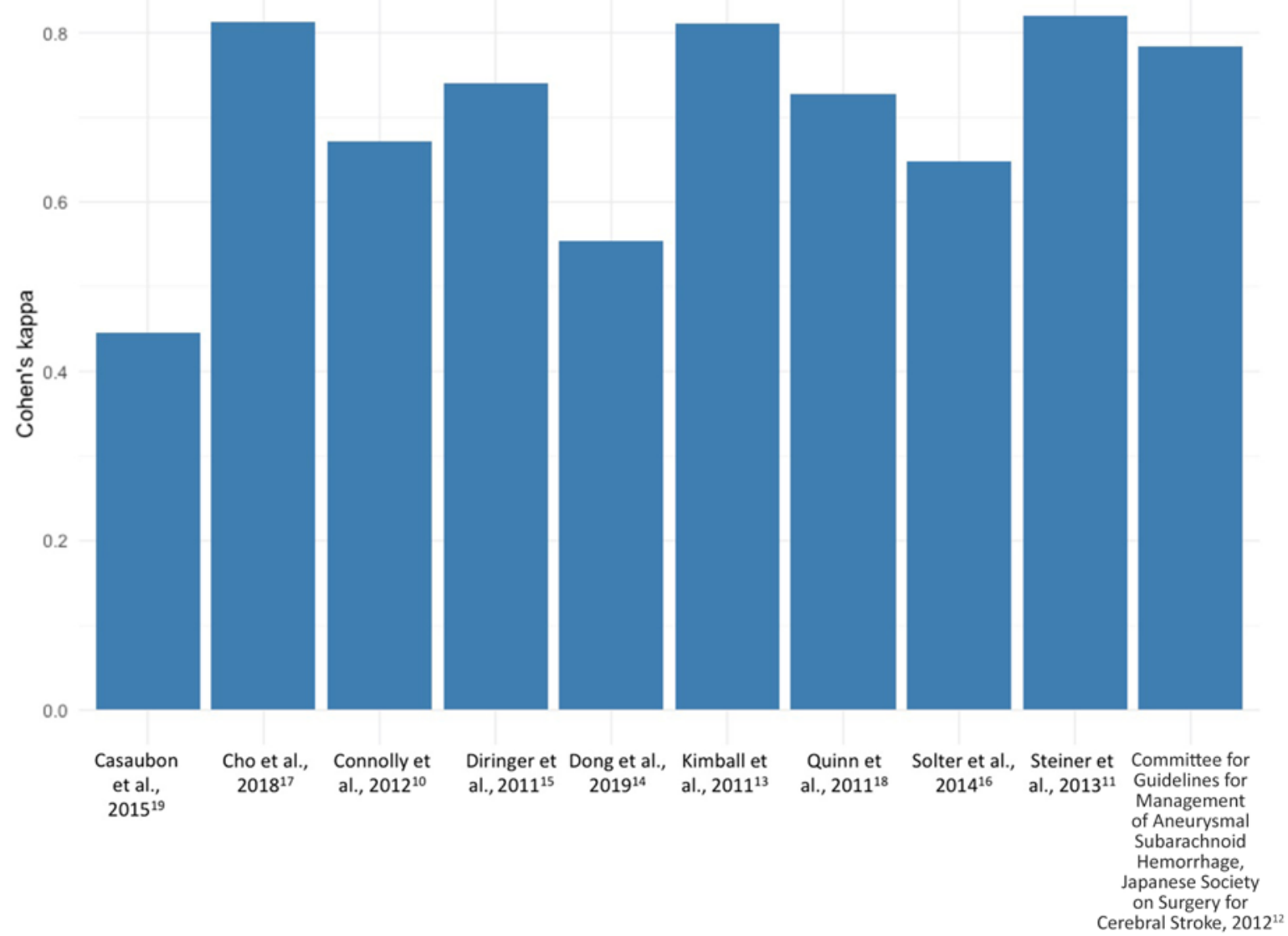

FIG. 2. Bar graph showing the interrater agreement for the scoring of the vasospasm guidelines. $0-0.19=$ no agreement, $0.20-0.39=$ minimal agreement, $0.40-0.59=$ weak agreement, $0.60-0.79=$ moderate agreement, $0.80-0.90=$ strong agreement, and $>0.90=$ almost perfect agreement. The raters showed the highest agreement in scoring the ESO guidelines by Steiner et al. ${ }^{11}$

evidence-based approach to the existing, pertinent literature. The association between the literature evidence and the guidelines is of utmost importance. Results of the current analysis may offer insight to the reader regarding editorial independence, as well as any potential stakeholder involvement. The results may also provide feedback to the recommendation developers on the fulfillment of their original scope and estimation on how well their purpose has been served. Our results stress the importance of involvement of multiple disciplines in the development of vasospasm management guidelines. Our findings related to the extremely low editorial independence of the existing guidelines emphasize the necessity of clearly stating all funding bodies, as well as the importance of addressing any potential competing interests.

\section{Areas of Improvement of Published Guidelines}

Several of the existing guidelines were published between 2011 and 2015. ${ }^{10-13,15,18}$ Likewise, the revised editions of previously published guidelines were updated during the same time, following rapid evolution in the field of endovascular treatment. ${ }^{10,19}$ Thus, most of the new or revised recommendations had to incorporate novel and advanced endovascular techniques with rapidly accumulating supporting clinical data. This resulted in major changes in the management of cerebral vasospasm. Characteristically, the
2012 AHA/ASA updated guidelines have adopted three new recommendations targeting vasospasm, among 22 new recommendations. Similarly, in a total of 9 revised recommendations, 3 referred to the management of vasospasm. ${ }^{10}$

Moreover, the guidelines are based on systematic review of pertinent literature. Although the intention of the issuing bodies is to update every 2 to 3 years, our current search revealed that only 3 records are updates of previously reported recommendations. ${ }^{22-24}$ The importance of updated data is reflected in the rigor of development domain of the AGREE-II tool, which was found to be low in the current analysis.

According to our findings, the gathered body of guidelines was of low methodological clarity in terms of stakeholder involvement, applicability, and editorial independence. Thus, based on our current findings, the writing and the target group (stakeholder involvement) should be better defined. Moreover, the designing and formatting of guidelines and their associated recommendations (including user-friendly checklists, easy-flow algorithms, periodic auditing, and well-defined barriers and facilitators) should be as simple as possible, thus increasing their reporting clarity and clinical applicability. It is also known that guidelines are usually developed with external funding; therefore, it is important for authors to state explicitly that the final recommendations have not been influenced 


\begin{tabular}{|c|c|c|c|c|c|c|c|c|c|c|c|c|c|c|c|c|c|c|c|c|c|c|c|}
\hline \multirow[b]{2}{*}{ Authors \& Year } & \multicolumn{7}{|c|}{ Diagnosis } & \multicolumn{11}{|c|}{ Medical Treatment } & \multicolumn{5}{|c|}{ Intervention } \\
\hline & 仓 & $\underset{\sigma}{\leftrightarrows}$ & 号 & $\overline{\underline{x}}$ & 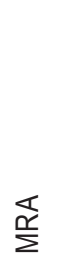 & $\frac{o}{\frac{\underline{x}}{\Sigma}}$ & 芯 & 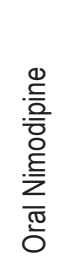 & 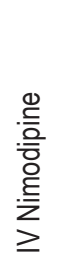 & 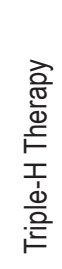 & 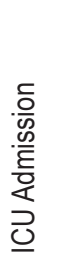 & 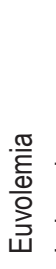 & 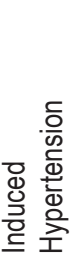 & 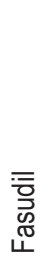 & 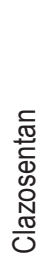 & 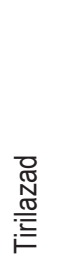 & 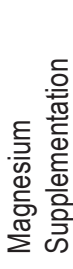 & 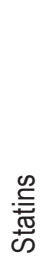 & 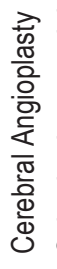 & 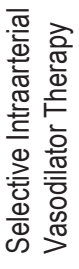 & 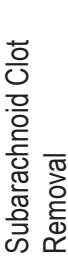 & 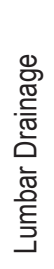 & 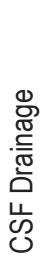 \\
\hline Diringer et al., $2011^{15}$ & $\mathrm{R}$ & - & $\mathrm{R}$ & - & - & - & $\mathrm{R}$ & $\mathrm{R}$ & - & $\mathrm{R}$ & $\mathrm{R}$ & - & - & - & - & - & - & - & $\mathrm{R}$ & $\mathrm{R}$ & - & - & - \\
\hline Quinn et al., 201118 & - & - & - & - & - & - & - & $\mathrm{R}$ & - & $\mathrm{R}$ & - & - & - & - & - & - & - & - & - & - & - & - & - \\
\hline Kimball et al., $2011^{13}$ & - & - & - & - & - & - & - & - & - & - & - & - & - & - & - & - & - & - & $\mathrm{R}$ & $\mathrm{R}$ & - & - & - \\
\hline Connolly et al., $2012^{10}$ & $\mathrm{R}$ & - & $\mathrm{R}$ & - & - & $\mathrm{R}$ & - & $\mathrm{R}$ & - & - & - & $\mathrm{R}$ & $\mathrm{R}$ & - & - & - & - & - & $\mathrm{R}$ & $\mathrm{R}$ & - & - & - \\
\hline $\begin{array}{l}\text { Committee for Guidelines for } \\
\text { Management of Aneurysmal } \\
\text { Subarachnoid Hemorrhage, } \\
\text { Japanese Society on Surgery } \\
\text { for Cerebral Stroke, } 2012^{12}\end{array}$ & $\mathrm{R}$ & $\mathrm{R}$ & - & $\mathrm{R}$ & $\mathrm{R}$ & - & - & NS & NS & $\mathrm{R}$ & - & - & $\mathrm{R}$ & $\mathrm{R}$ & - & - & - & - & $\mathrm{R}$ & $\mathrm{R}$ & $\mathrm{R}$ & - & - \\
\hline Steiner et al., $2013^{11}$ & - & - & - & - & - & - & - & $\mathrm{R}$ & $\mathrm{R}$ & NR & - & - & - & - & - & - & NR & $\mathrm{R}$ & - & - & - & - & - \\
\hline Solter et al., $2014^{16}$ & $\mathrm{R}$ & $\mathrm{R}$ & $\mathrm{R}$ & - & - & - & $\mathrm{R}$ & $\mathrm{R}$ & - & NR & - & $\mathrm{R}$ & $\mathrm{R}$ & - & - & - & NR & $\mathrm{R}$ & $\mathrm{R}$ & $\mathrm{R}$ & - & - & - \\
\hline Casaubon et al., $2015^{19}$ & - & - & - & - & - & - & - & - & - & - & - & $\mathrm{R}$ & $\mathrm{R}$ & - & - & - & - & - & $\mathrm{R}$ & $\mathrm{R}$ & - & - & - \\
\hline Cho et al., $2018^{17}$ & $\mathrm{R}$ & $\mathrm{R}$ & - & - & - & - & $\mathrm{R}$ & $\mathrm{R}$ & - & - & - & - & $\mathrm{R}$ & - & - & - & - & - & $\mathrm{R}$ & - & - & $\mathrm{R}$ & - \\
\hline Dong et al., $2019^{14}$ & - & - & - & - & - & - & - & $\mathrm{R}$ & $\mathrm{R}$ & - & - & - & - & $\mathrm{R}$ & $\mathrm{R}$ & $\mathrm{R}$ & - & - & $\mathrm{R}$ & - & - & - & $\mathrm{R}$ \\
\hline
\end{tabular}

CTP = CT perfusion; ICU = intensive care unit; IV = intravenous; MRP = MR perfusion; NR = not recommended; $N S=$ not specified; $R=$ recommended; $-=$ not reported.

by the views or interests of the funding bodies (i.e., editorial independence). The concept of external reviewing of the guidelines represents another aspect of future improvement. The mean clarity of presentation (78.3\%) and mean overall guideline assessment $(61.7 \%)$ were of medium quality, while the mean quality of scope and purpose was found to be high (81\%). All these domains may be further improved in future updates of current guidelines or new publications.

\section{Overall Agreement Assessment}

To evaluate the overall assessment of the guidelines, it is necessary to estimate the overall agreement of the appraisals. It is well known that AGREE-II is largely based on objective judgment; therefore, there is risk of high interrater disagreement. Accordingly, we increased the number of raters to three and conducted all proper adjustments in domain scoring. In our study, the overall agreement between raters was moderate. There was a strong agreement in scoring the ESO as well as the Korean guidelines. Likewise, there was strong agreement with regard to the low overall assessment of the International Multidisciplinary Consensus guidelines by Kimball et al. It is of interest that interrater agreement was weak regarding the overall assessment of the Canadian stroke best practice recommendations.

\section{Study Limitations}

Our current appraisal study has some important limitations. First, we searched for guidelines and recommendations written only in the English language. Moreover, our search was further limited to guidelines published in peer-reviewed journals. Second, the majority of gathered guidelines focused on SAH and stroke, while only a few were dedicated to vasospasm management. Nevertheless, this approach is supported by AGREE-II. Third, AGREEII constitutes an objective tool; however, there is no other validated tool available for appraising guidelines. Additionally, as mentioned earlier, a moderate interrater agreement was observed.

\section{Conclusions}

The clinical value of evidence-based guidelines cannot be overemphasized. The existence of guidelines may guarantee the early diagnosis and proper management of aSAH-associated vasospasm. It may also promote communication and collaboration among physicians managing these patients and serve as a guiding compass, particularly for younger physicians. The publication of clear and updated guidelines may also provide clinicians with a helpful tool for defensible medical practice. It is apparent that future guidelines need to be characterized by high methodological quality and reporting clarity; in the current study, the AHA/ASA guidelines obtained the highest scores. Additionally, future guidelines must be independent of any sponsoring influences, periodically updated, and constantly and externally assessed.

\section{References}

1. Velthuis BK, Rinkel GJ, Ramos LM, et al. Subarachnoid hemorrhage: aneurysm detection and preoperative evaluation with CT angiography. Radiology. 1998;208(2):423-430. 
2. Feigin VL, Lawes CM, Bennett DA, Barker-Collo SL, Parag V. Worldwide stroke incidence and early case fatality reported in 56 population-based studies: a systematic review. Lancet Neurol. 2009;8(4):355-369.

3. Nieuwkamp DJ, Setz LE, Algra A, Linn FH, de Rooij NK, Rinkel GJ. Changes in case fatality of aneurysmal subarachnoid haemorrhage over time, according to age, sex, and region: a meta-analysis. Lancet Neurol. 2009;8(7):635-642.

4. Sobey CG, Faraci FM. Subarachnoid haemorrhage: what happens to the cerebral arteries? Clin Exp Pharmacol Physiol. 1998;25(11):867-876.

5. Hop JW, Rinkel GJ, Algra A, van Gijn J. Case-fatality rates and functional outcome after subarachnoid hemorrhage: a systematic review. Stroke. 1997;28(3):660-664.

6. Weir B. Subarachnoid Hemorrhage: Causes and Cures. Oxford University Press; 1998.

7. Kassell NF, Sasaki T, Colohan ART, Nazar G. Cerebral vasospasm following aneurysmal subarachnoid hemorrhage. Stroke. 1985;16(4):562-572.

8. Ho HW, Batjer HH. Aneurysmal subarachnoid hemorrhage: pathophysiology and sequelae. In: Batjer HH, ed. Cerebrovascular Disease. Lippincott-Raven Publishers; 1997:889899.

9. Brouwers MC, Kho ME, Browman GP, et al. AGREE II: advancing guideline development, reporting and evaluation in health care. CMAJ. 2010;182(18):E839-E842.

10. Connolly ES Jr, Rabinstein AA, Carhuapoma JR, et al. Guidelines for the management of aneurysmal subarachnoid hemorrhage: a guideline for healthcare professionals from the American Heart Association/American Stroke Association. Stroke. 2012;43(6):1711-1737.

11. Steiner T, Juvela S, Unterberg A, Jung C, Forsting M, Rinkel G. European Stroke Organization guidelines for the management of intracranial aneurysms and subarachnoid haemorrhage. Cerebrovasc Dis. 2013;35(2):93-112.

12. Committee for Guidelines for Management of Aneurysmal Subarachnoid Hemorrhage, Japanese Society on Surgery for Cerebral Stroke. Evidence-based guidelines for the management of aneurysmal subarachnoid hemorrhage. English Edition. Neurol Med Chir (Tokyo). 2012;52(6):355-429.

13. Kimball MM, Velat GJ, Hoh BL. Critical care guidelines on the endovascular management of cerebral vasospasm. Neurocrit Care. 2011;15(2):336-341.

14. Dong Y, Guo ZN, Li Q, et al. Chinese Stroke Association guidelines for clinical management of cerebrovascular disorders: executive summary and 2019 update of clinical management of spontaneous subarachnoid haemorrhage. Stroke Vasc Neurol. 2019;4(4):176-181.

15. Diringer MN, Bleck TP, Claude Hemphill J III, et al. Critical care management of patients following aneurysmal subarachnoid hemorrhage: recommendations from the Neurocritical Care Society's Multidisciplinary Consensus Conference. Neurocrit Care. 2011;15(2):211-240.
16. Solter VV, Roje-Bedeković M, Breitenfeld T, et al. Recommendations for the management of medical complications in patients following aneurysmal subarachnoid hemorrhage. Acta Clin Croat. 2014;53(1):113-138.

17. Cho WS, Kim JE, Park SQ, et al. Korean clinical practice guidelines for aneurysmal subarachnoid hemorrhage. $J \mathrm{Ko}$ rean Neurosurg Soc. 2018;61(2):127-166.

18. Quinn AC, Hall G, Marsh S, Clark M, Ross S. Evidenced based guidelines for the management of good grade subarachnoid haemorrhage patients in Leeds, UK. Acta Neurochir Suppl (Wien). 2011;110(Pt 2):161-164.

19. Casaubon LK, Boulanger JM, Blacquiere D, et al. Canadian stroke best practice recommendations: hyperacute stroke care guidelines, update 2015. Int J Stroke. 2015;10(6):924-940.

20. Allen GS, Ahn Hs, Preziosi TJ, et al. Cerebral arterial spasm - a controlled trial of nimodipine in patients with subarachnoid hemorrhage. N Engl J Med. 1983;308(11):619-624.

21. Dorhout Mees SM, Rinkel GJE, Feigin VL, et al. Calcium antagonists for aneurysmal subarachnoid haemorrhage. $\mathrm{Co}$ chrane Database Syst Rev. 2007;(3):CD000277.

22. Mayberg MR, Batjer HH, Dacey R, et al. Guidelines for the management of aneurysmal subarachnoid hemorrhage. A statement for healthcare professionals from a special writing group of the Stroke Council, American Heart Association. Stroke. 1994;25(11):2315-2328.

23. Bederson JB, Connolly ES Jr, Batjer HH, et al. Guidelines for the management of aneurysmal subarachnoid hemorrhage: a statement for healthcare professionals from a special writing group of the Stroke Council, American Heart Association. Stroke. 2009;40(3):994-1025.

24. Findlay JM. Current management of aneurysmal subarachnoid hemorrhage guidelines from the Canadian Neurosurgical Society. Can J Neurol Sci. 1997;24(2):161-170.

\section{Disclosures}

The authors report no conflict of interest concerning the materials or methods used in this study or the findings specified in this paper.

\section{Author Contributions}

Conception and design: Fountas. Acquisition of data: all authors. Analysis and interpretation of data: all authors. Drafting the article: Tasiou, Brotis, Fountas. Critically revising the article: Fountas. Reviewed submitted version of manuscript: all authors. Approved the final version of the manuscript on behalf of all authors: Tasiou. Study supervision: Fountas.

\section{Correspondence}

Anastasia Tasiou: University Hospital of Larissa, Greece. ttasiou@yahoo.com. 